\title{
O SIGNIFICADO DO SÍTIO DE ADERÊNCIA DAS LÊNDEAS DE PEDICULUS CAPITIS EM AMOSTRAS DE CABELOS RECOLHIDAS DO CHÃO DE BARBEARIAS
}

\author{
Pedro Marcos Linardi1, José Ramiro Botelho, Mário \\ de Maria ${ }^{2}$ e Horácio Capistrano Cunha ${ }^{3}$
}

\begin{abstract}
Foram realizadas observaçóes sobre o sitio de aderência de 3178 lêndeas em cabelos cortados e colhidos de 475 barbearias de Belo Horizonte - se na base, meio ou extremidade - e sobre o estado de viabilidade das mesmas (lêndeas formadas ou desenvolvidas). $A$ direção do opérculo foi tomada como referência para determinação desta posição. Em outros 66 fios de cabelo foram encontradas 140 lêndeas em infestaçóes duplas ou múltiplas. Estes dados nos permitiram estimar, de modo grosseiro, o periodo da infestação ao tempo do corte de cabelo (7-10 dias, em média), o tempo decorrido entre reinfestações consecutivas (21-25 dias, no mínimo), bem como em que proporção os cortes foram efetuados ou como medida de controle para tentar conter a infestação $(28,8 \%)$, ou após a infestação haver sido debelada (71,2\%).
\end{abstract}

Palavras chaves: Pediculus capitis. Pediculose. Piolhos. Lêndeas. Minas Gerais.

Em Pediculus capitis De Geer (= Pediculus humanus capitis), a oviposição é realizada na base dos cabelos humanos, com a parte basal dos ovos envolvendo o eixo dos cabelos através de uma substância aglutinante, segregada pelas glândulas acessórias da fêmea ${ }^{3}$. Este cemento apresenta uma consistência rígida, não se conhecendo, até o presente, substância ou processo algum capaz de dissolvê-lo, sem que acarrete prejuizos aos fios de cabelos parasitados ${ }^{28}$. Assim, à medida que, paulatinamente, os cabelos crescem, gradativamente, as lêndeas afastam-se do couro cabeludo.

Estas caracteristicas nos permitiram idealizar uma metodologia para determinação da prevalência da pediculose em comunidades, tendo-se por base o estudo das amostras de cabelos recolhidos do chão de barbearias e salões de beleza de Belo Horizonte, $\mathrm{MG}^{56}$.

O presente trabalho, tratando de observações realizadas em relação ao sítio do fio de cabelo cortado em que a localização das lêndeas era mais freqüente, permite avaliar, de modo grosseiro, junto às comunidades, parâmetros de especial valor para a epidemiologia e profilaxia da pediculose do couro cabeludo, como o espaço de tempo decorrido entre a instalação da

1. Departamento de Parasitologia, ICB, Universidade Federal de Minas Gerais.

Caixa Postal 2486 - 31270, Belo Horizonte, MG. Bolsistas do Conselho Nacional de Desenvolvimento Científico e Tecnológico (CNPq).

2. Departamento de Zoologia, ICB, Universidade Federal de Minas Gerais.

3. Departamento de Controle de Zoonoses, Secretaria Municipal de Saúde, Prefeitura de Belo Horizonte, MG.

Recebido para publicação em 20/5/87. infestação e o corte de cabelo subseqüente ou entre reinfestações consecutivas, bem como em que proporção os cortes foram realizados como medida de controle.

\section{MATERIAL E MÉTODOS}

As amostras de cabelo foram recolhidas do chão de 475 barbearias e salões de beleza, espalhados pelos mais diversos bairros e setores de Belo Horizonte, MG. No laboratório, após separação das amostras infestadas por ovos de piolhos, elas foram examinadas com o auxílio de uma lupa de mão ou microscópio estereoscópico para identificar o sítio de implantação das lêndeas na extensão do fio de cabelo cortado base/meio/extremidade - (Fig. 1) e o estado de via-
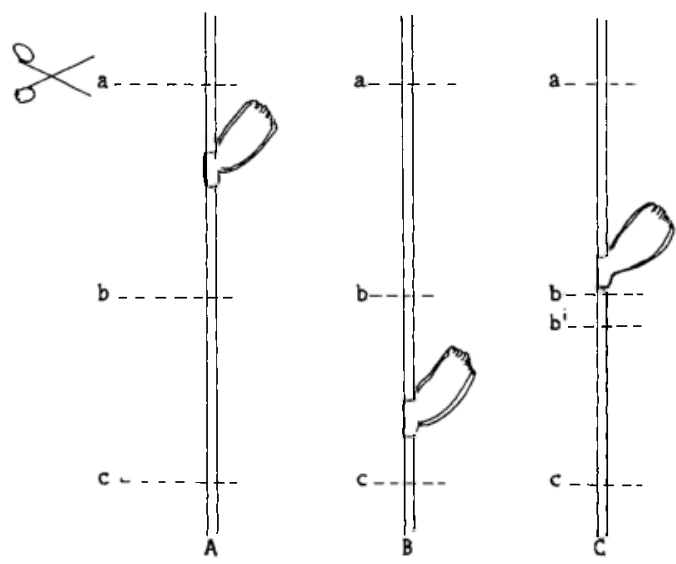

Fig. 1 - Segmentos de cabelo cortado col 1 ovos de Pediculus capitis implantados na:

$A$ - extremidade; $B$ - base; $C$ - região mediana. $(a, b, b$ ' $c$ indicam altura ou profundidade do corte efetuado). 
Linardi PM, Botelho JR, Maria M de, Cunha HC. O significado do sitio de aderência das lêndeas de Pediculus capitis em amostras de cabelos recolhidos do chão de barbearias. Revista da Sociedade Brasileira de Medicina Tropical 20: 209-212, Out-Dez, 1987

bilidade das mesmas: lêndeas formadas (com embrião interno) ou eclodidas. A direção do opérculo do ovo, que é sempre oposta ao couro cabeludo, foi o principal caráter empregado como critério da aferição da posição da lêndea no fio de cabelo cortado (base ou extremidade).

As observações foram realizadas em 3178 lêndeas implantadas, respectivamente, em 3178 diferentes segmentos encontrados nos quase $34 \mathrm{~g}$ de cabelo, coletados no periodo de outubro de 1984 a abril de 1985. Em outros 66 fios de cabelo foram ainda constatadas 140 lêndeas, porém albergando infestações duplas ou múltiplas. Nenhuma lêndea se fez notar em segmentos de cabelo inferiores a nove milímetros de comprimento.

\section{RESULTADOS}

Na Tabela 1 são apresentados dados relativos ao número e percentagem de lêndeas encontrados, respectivamente, junto à base, ao meio ou à extremidade dos segmentos de cabelo, bem como ao número e à proporção de lêndeas em relação ao caráter viabilidade, discriminados por sítios de implantação nos fios de cabelo cortado. $\mathrm{O}$ teste do qui-quadrado $\left(\mathrm{X}^{2}\right)$ foi utilizado para determinar o nível de significância da associação entre a viabilidade das lêndeas e o seu posicionamento ao longo dos segmentos de cabelo.

Tabela 1 - Localização e viabilidade de lêndeas observadas em amostras de cabelos cortados e recolhidos do chão de barbearias e similares, em Belo Horizonte, MG.

\begin{tabular}{lccccrcc}
\hline \multirow{2}{*}{$\begin{array}{l}\text { Sitio de } \\
\text { implantação no }\end{array}$} & $\begin{array}{c}\text { Formadas } \\
\text { cabelo cortado }\end{array}$ & $\begin{array}{c}\text { Eclodidas } \\
\text { (viaveis) }\end{array}$ & $\begin{array}{c}\text { \% de via- } \\
\text { (vilidade }\end{array}$ & $\begin{array}{c}\text { Não veri- } \\
\text { ficadas }\end{array}$ & Total & $\%$ \\
\hline Base & 38 & 327 & 10,4 & 394 & 759 & 23,9 \\
Meio & $620^{*}$ & 1020 & 37,8 & 289 & 1929 & 60,7 \\
Extremidade & 27 & 346 & 7,2 & 117 & 490 & 15,4 \\
\hline Total & 685 & 1693 & 28,9 & 800 & 3178 & 100,0 \\
\hline
\end{tabular}

*P<0,001

\section{DISCUSSÃO}

Considerando que, à medida que os cabelos crescem, as lêndeas distanciam-se do couro cabeludo, uma aplicação prática do estudo da localização das lêndeas junto aos fios de cabelos seria a determinação relativa da idade da infestação. Investigando-se segmentos de cabelo cortado, um estudo pormenorizado para estimativas mais aproximadas, necessariamente deveria incluir as seguintes medidas: a) comprimento de todos os fios de cabelos parasitados das pessoas infestadas, anteriores ao corte; b) distância, a partir da base do couro cabeludo, para cada golpe do instrumento cortante (tesoura, máquina, navalha); c) comprimento de todos os segmentos infestados e resultantes do corte. Pela sua dificuldade de execução na prática e complexidade, como p. ex., manutenção de uma distância uniforme de corte, tempo gasto para observações, um tal programa seria praticamente inexeqüivel.

A simples aferição da posição de uma lêndea ao longo de um segmento de cabelo cortado é totalmente relativa, como se pode depreender da Fig. 1 apresentada. Assim, se em $A$, o primeiro golpe for mais profundo que superficial - ao nivel $B$ - o segmento resultante apresentará a lêndea situada ao meio, antes que à extremidade $e$, conseqüentemente, alterada de sua posi- ção original no fio de cabelo. Já em $C$, um primeiro golpe (a) não alcançaria o sítio parasitado, mas se porventura este mesmo fio for atingido por um segundo golpe (b), entāo, o segmento de cabelo resultante, apresentando uma lêndea supostamente implantada em sua base, simulará uma infestação mais recente do que a original!...

Mas esses mesmos segmentos poderiam proporcionar idades grosseiras das infestações, tornando o método ajustado para aplicação prática se, juntamente com a observação da posição, fosse também determinado o estado de viabilidade das lêndeas encontradas, além de utilizados alguns conhecimentos sobre o ciclo biológico dos piolhos - como duração média e periodo de incubação dos ovos - e sobre o tempo médio de crescimento dos cabelos. $O$ ciclo biológico de $P$. capitis é de aproximadamente 3-4 semanas, com a eclosão do 10 estádio ninfal ocorrendo aos 8-9 dias ${ }^{1} 24$. Para Maunder ${ }^{7}$, os cabelos crescem na razão média de $1,3 \mathrm{~cm} / \mathrm{mês}$.

Assim, em face de tais dados e aos da Tabela 1, poderia ser estabelecido que:

1) A distância "virtual" de uma lêndea ao couro cabeludo seria, ao tempo de sua incubação, aproximadamente de $4-5 \mathrm{~mm}$ ou, no máximo, de $7-8 \mathrm{~mm}$, mesmo considerando um periodo de incubação pro- 
Linandi PM, Botelho JR, Maria M de, Cunha HC. O significado do sítio de aderência das lêndeas de Pediculus capitis em amostras de cabelos recolhidos do chāo de bärbearias. Revista da Sociedade Brasileira de Medicina Tropical 20: 209-212, Out-Dez, 1987

longado ou uma velocidade mais rápida de crescimento do cabelo. Nenhuma lêndea viável seria, pois, encontrada, além desta distância. Esta seria, para Maunder ${ }^{7}$, a distância limite da ação do calor da cabeça, indispensável ao desenvolvimento do ovo.

2) As percentagens de lêndeas viáveis, encontradas, respectivamente, na base ou na extremidade dos segmentos de cabelo cortado, embora sejam semelhantes, resultam em diferentes explicações. Segmentos com lêndeas viáveis situadas em suas extremidades devem ter sido originados a partir de um segundo golpe, em fios de cabelo com lêndeas originalmente dispostas pela região central. Segmentos albergando lêndeas viáveis junto à parte basal só poderiam ser originados em razão de um golpe profundo no fio de cabelo portador de uma infestação inicial (Fig. $1 B$ nivel $c$ ), ou a partir de um segundo golpe como ao nivel $b$ ou $b$ ' da Fig. $1 C$.

3) Como a maior percentagem de lêndeas formadas fez se notar mais significativamente na parte mediana dos segmentos $(P<0,001)$ (Tabela 1 ), antes que na parte basal, ou mesmo na parte basal + distal desses segmentos, e como também nenhuma lêndea foi encontrada em segmentos de cabelos inferiotes a $9 \mathrm{~mm}$ de comprimento (e mesmo nesse caso, a lêndea ainda que ao centro, determinaria, pelo menos, uns 4 ou $5 \mathrm{~mm}$ de sobra de cabelo, em cada lado), conclui-se que o tempo médio decorrido entre a aquisição da pediculose e o corte de cabelo subseqüente foi de, aproximadamente, 7-10 dias.

4) A maior parte das lêndeas $(71,2 \%)$ independentemente de sua alocação no fio de cabelo, sendo já ovos esvaziados (Tabela 1), permite supor que grande parte da população deva ter se utilizado do corte após a infestação haver sido debelada e/ou como medida complementar para remoção das cascas dos ovos após determinado controle terapêutico direcionado aos piolhos adultos. Se apenas $28,8 \%$ dos fios parasitados, procedentes de diversas amostras, eram portadores de lêndeas viáveis, no máximo, esta mesma proporção da população deve ter feito uso do corte, como medida de controle natural, para conter a infestação, ainda em curso. A propósito, o corte de cabelos como medida de controle da pediculose só teria valor se realizado até a distância limite de $0,8 \mathrm{~cm}$ a partir do couro cabeludo, tendo-se em vista o espaço dinâmico para os piolhos se locomoverem, fixarem-se aos pêlos e efetuarem a oviposição ${ }^{7}$.

5) Algumas amostras com infestações mistas (lêndeas e adultos; lêndeas e ninfas; lêndeas, ninfas e adultos) poderiam, conseqüentemente, ser datadas de, no minimo 21-25 dias. Em apenas duas amostras, das 140 infestadas, foram encontradas exclusivamente insetos adultos, o que poderia ser atribuido a infestações recentes, ou unissexuadas.
6) Naqueles fios de cabelo onde foi constatada mais de uma lêndea, o espaçamento entre elas seria fundamental para decisões acerca de infestações maciças ainda em curso, ou atribuidas a reinfestações. Em geral, os piolhos ovipõem uma única lêndea na base de cada fio de cabelo, salvo em infestações de grande porte, onde centenas ou milhares de piolhos disputam cada fração de espaço para sua sobrevivência. Nesse caso, o espaçamento entre os ovos seria bem reduzido, e todos ou quase todos eles ainda em condições viáveis para eclosão. Em se tratando de reinfestações, a distância entre as lêndeas deveria ser maior-pelo menos superior a $1,3-1,5 \mathrm{~cm}-$ com aquelas mais distais já se apresentando vazias.

Seria de interesse enfatizar que a inspeção da cabeça é ainda o melhor método para diagnóstico, determinação da idade relativa da infestação e avaliação da eficácia de piolhicidas, quando aplicada individualmente ou a pequenos agrupamentos. Julgamos, contudo, que a metodologia e resultados aqui apresentados possam auxiliar ao entomologista ou ao sanitarista quando necessitarem estender suas observaçōes a comunidades maiores ou retirar ilações acerca de populações.

\section{SUMMARY}

In 3,178 nits of Pediculus capitis attached in different cut hair and collected from floors of barbershops samples in Belo Horizonte, Minas Gerais State, observations were made on the point of attachement of these nits in relation to the cut hair segments - if in the base, middle or extremity - as well as on the state of development of them (nits developed or empty). The direction of the operculum was assumed as a criterium for determining of this place. Another 66 cut hairs segments presented 140 nits in double or multiple infestations. These data can help us to estimate, roughly, the relative age of the infestation at the time of the haircut (7-10 days, in average), the time spent among consecutive reinfestations' (21-25 days, at least), as well as in that proportion the haircuts were made as a control measure for the breaking of the infestation (28.8\%), or after the pediculosis has already been overcame (71.2\%).

Key words: Pediculus capitis. Pediculosis. Lice. Nits. Minas Gerais State.

\section{REFERÊNCIAS BIBLIOGRÁFICAS}

1. Busvine JR. The "head" and "body" races of Pediculus humanus L. Parasitology 39: 1-16, 1984.

2. Busvine JR. Insects and Hygiene. Methuen \& Co Ltd, London, 1966.

3. Ferris GF. The sucking lice. Memoirs of the Pacific Coast Entomological Society 1: 1-320, 1951. 
Linardi PM, Botelho JR, Maria M de, Cunha HC. O significado do sitio de aderência das lêndeas de Pediculus capitis em amostras de cabelos recolhidos do chão de barbearias. Revista da Sociedade Brasileira de Medicina Tropical 20: 209-212, Out-Dez, 1987

4. Hopkins GHE. The host-association of lice of mammals. Proceedings of the Zoological Society of London 119: 387-604, 1949.

5. Linardi PM. Menos higiene, mais piolhos. Ciência Hoje 4: $10-11,1985$.

6. Linardi PM, De Maria M, Botelho JR, Cunha HC, Ferreira JB, Mata ER. Dados qualitativos e quantitativos sobre piolhos observados em amostras de cabelos reco- lhidas em salões de barbeiro em Belo Horizonte, MG. In: Resumos do IX Congresso da Sociedade Brasileira de Parasitologia, Fortaleza p. 160, 1985.

7. Maunder JW. Human lice - biology and control. Royal Society of Health Journal 97: 29-32, 1977.

8. Pratt HD, Littig KS. Lice of Public Health Importance and their Control. DHEW Publication No CDC 798265, Atlanta, 1973. 